\section{SOI: $1.1 /$ TAS DOI: $10.15863 / \mathrm{TAS}$ International Scientific Journal Theoretical \& Applied Science}

p-ISSN: 2308-4944 (print) e-ISSN: 2409-0085 (online)

Year: $2018 \quad$ Issue: $03 \quad$ Volume: 59

Published: $30.03 .2018 \quad$ http://T-Science.org
Mariya Kasimbaevna Sayakova doctor of juridical science, acting professor first vice-rector of Institute of Modern Information Technologies in Education of Kyrgyz Republic

\section{Ailen Dokturbekovna Adambekova doctor of juridical science \\ Senior Researcher of Academy of Ministry of Interrior Affairs of Kyrgyz Republic}

SECTION 32. Jurisprudence.

\title{
VICTIMOLOGICAL PREVENTION OF WOMEN CRIME
}

Abstract: The article reviews the results of many criminological studies on the prevention of female crime and presents the results of a local study among convicted women in order to establish a propensity to victim behavior.

Key words: criminological characteristics of female crime, prevention of female crime, motivational and behavioral characteristics of victims, victim behavior, female crime.

Language: Russian

Citation: Sayakova MK, Adambekova AD (2018) VICTIMOLOGICAL PREVENTION OF WOMEN CRIME. ISJ Theoretical \& Applied Science, 03 (59): 223-226.

Soi: http://s-o-i.org/1.1/TAS-03-59-37 Doi: crossef https://dx.doi.org/10.15863/TAS.2018.03.59.37

\section{ВИКТИМОЛОГИЧЕСКАЯ ПРОФИЛАКТИКА ЖЕНСКОЙ ПРЕСТУПНОСТИ}

Аннотация: В статье рассматривается результаты многих криминологических исследований по предупреждению женской преступности и приведены результаты локального исследования среди осужденных женщин в иелях установления склонности к виктимному поведению.

Ключевые слова: криминологическая характеристика женской преступности, профилактика женской преступности, мотивационная и поведенческая характеристика потерпевших, виктимное поведение, женская преступность.

\section{Introduction}

В механизме преступлений, совершенных женщиной, часто решающую роль играют отношения, в которых находятся потерпевший и преступница. Достаточно указать на так называемую бытовую преступность, в которой наиболее ярко проявляются стабильные отношения между преступницей и потерпевшим. Потерпевший может вести себя так, что вольно или невольно способствует совершению преступления против себя [1, с. 27].

Криминологическая значимость виктимного поведения не связана только лишь с активностью и негативной мотивацией. Пассивное, некритичное поведение, положительная мотивация действия или бездействия потерпевшего тоже играют свою роль в механизме преступления [2, с. 406].

В то же время не возникает особых разногласий по поводу признания потенциально виктимными таких типов поведения, как пассивное или неосторожное поведение. Например, такое поведение характеризует лиц, не способных оказать сопротивление в силу возраста, беспомощного состояния, трусости.
Чаще всего такого типа поведение характерно для лиц, находящихся в родственных отношениях, или в определенной зависимости от посягающего лица.

Что касается неосторожного поведения, то его часто демонстрируют лица, не умеющие правильно оценить ту или иную конкретную ситуацию. Например, к этому типу относят несоблюдение мер предосторожности при вступлении в интимные отношения, например, ввиду опасности заражения ВИЧ-инфекцией.

\section{Materials and Methods}

С учетом мотивационной и поведенческой характеристики потерпевших от преступлений, совершенных женщинами, в литературе [3, с. 94] выделяются такие подтипы, как корыстный, сексуальный, семейные деспоты. В таких случаях, вина женщины, совершившей преступление, находится в непосредственной зависимости от преступного поведения жертвы преступления. Осознание неправомерности, угрожающего характера действий потерпевшего вызывает у преступницы состояние психической напряженности, которое способствует ответному 
проявлению агрессии. Так, по данным различных виктимологических исследований поведения потерпевших по делам о преступлениях против личности, каждый третий потерпевший по делу об убийствах, совершенных женщинами, участвовал в виновной обоюдной ссоре или совершил в отношении нее противоправные действия. При этом более половины находились в состоянии опьянения [4, с. 73$]$.

Результаты многих криминологических исследований утверждают, что совершению преступлений чаще всего предшествует так называемая активная провокация, т.е. оскорбления, угрозы, побои, издевательства, клеветнические измышления со стороны потерпевшего, а также поступки, направленные против причинителя вреда, его близких. Такие действия вольно или невольно ведут к созданию конфликтной ситуации. Самих же потерпевших в данном случае можно охарактеризовать как агрессивных людей с вызывающим поведением. В частности, к ним относятся семейные деспоты, применяющие физическое насилие к своим близким, скандалисты, конфликтующие с соседями. Такие люди часто создают обстановку, невозможную для совместного проживания. А те, кто страдают от их деспотизма предпочитают не сообщать об этом в правоохранительные органы, считая такие деяния недостаточно преступными либо боясь огласки или по иным мотивам. Именно поэтому конфликты становятся хроническими и, в конце концов, могут закончиться нанесением вреда здоровью или даже убийством.

Наиболее часто в ситуациях подобного рода наблюдается тип семейного деспота. В таких случаях женщины, совершившие преступления в отношении семейных деспотов, «характеризуются положительно, а их действия имеют вынужденный характер: систематические избиения, издевательства со стороны семейных деспотов порождают отчаяние, убеждение в том, что иного выхода, кроме защиты крайними средствами, нет» [3, с. 94].

Такие же данные получены в связи с проблемой наркомании как фонового явления. Несмотря на то, что зависимые от наркотиков люди обычно менее агрессивны, за исключением состояния абстиненции («ломки»), их поведение рассматривается также как фактор, имеющий значение для виктимологических исследований [5, c. 22].

Для виктимологического изучения проблем женской преступности является важным в этой связи и изучение того, насколько сами преступницы могут быть охарактеризованы в качестве виктимного типа личности. Мы воспользовались методикой Малкиной-Пых И.Г. [2, с. 156-160] Для этого нами было проведено локальное исследование среди осужденных женщин в целях установления склонности к виктимному поведению. Текст опросника обрабатывался в несколько процедур, который переводился на примере Шкалы социальной желательности ответов. Если показатели по данной шкале ниже нормы (1-3 стен), очевидно, что испытуемая нечасто попадает в критические ситуации либо у нее уже успел выработаться защитный стиль поведения, позволяющий избегать конфликтных ситуаций. Однако внутренняя готовность к виктимному способу поведения присутствует. Скорее всего, ощущая внутренний уровень напряжения, она стремится вообще избегать ситуации конфликта. В проведенном нами исследовании выяснилось, что этот уровень у опрошенных осужденных женщин оказался значительно ниже нормы и составил $6,6 \%$.

Это означает, что испытуемые имели склонность попадать в неприятные или даже опасные для здоровья и жизни ситуации. Причиной этого является внутренняя предрасположенность и готовность личности действовать определенными, ведущими в индивидуальном профиле способами. Чаще всего это выражалось в стремлении к агрессивному, необдуманному действию спонтанного характера. Показатель составил 53\%, тогда как норма $33,3 \%$.

К группе, склонной к агрессивному поведению, относятся опрошенные, склонные попадать в неприятные и опасные для жизни и здоровья ситуации в результате проявленной агрессии в форме нападения или иного провоцирующего поведения (оскорбление, клевета, издевательство и т. д.). Здесь показатели достигли 66\%. Для них характерно намеренное создание или провоцирование конфликтной ситуации. Их поведение может быть реализацией типичной для них антиобщественной направленности личности, в рамках которой агрессивность проявляется по отношению к определенным лицам и в определенных ситуациях (избирательно), но может быть и «размытой», не персонифицированной по объекту. Наблюдается склонность к антиобщественному поведению, нарушению социальных норм, правил и этических ценностей, которыми зачастую субъект пренебрегает. Такие люди легко поддаются эмоциям, особенно негативного характера, ярко их выражают, доминантны, нетерпеливы, вспыльчивы [7, с. 58]. При всех различиях в мотивации поведения характерно наличие насильственной антиобщественной установки личности.

Ниже нормы-20\% (26,6\%) выявлен показатель, характеризующий пассивность, равнодушие к тем явлениям, которые происходят 
вокруг. Обычно такой тип личности действует по принципу «моя хата с краю», что может быть последствием как обиды на внешний мир, так и ощущения непонимания, изолированности от мира, отсутствия чувства социальной поддержки и включенности в социум.

Ниже нормы (20\%) оказался такой показатель, как склонность к независимости, обособленности. Всегда стремится выделиться из группы сверстников, имеет на все свою точку зрения, может быть непримирим к мнению других, авторитарен, конфликтен. Повышенный скептицизм. Возможна внутренняя ранимость, приводящая к повышенному желанию обособиться от окружающих [8, с. 142].

Показатель выше нормы - $80 \%$ свидетельствует о том, что испытуемые представляют собой лица, демонстрирующие неосмотрительность, неумение правильно оценивать жизненные ситуации. Эти лица демонстрируют неосторожность, неосмотрительность, неумение правильно оценивать жизненные ситуации в результате каких-либо личностных или ситуативных факторов: эмоциональное состояние, возраст, уровень интеллекта, заболевание.

Личность некритичного типа обнаруживает склонность к спиртному, неразборчивость в знакомствах, доверчивость, легкомысленность. Имеет непрочные нравственные устои, что усиливается отсутствием личного опыта или его недоучет. Склонны к идеализации людей, оправданию негативного поведения других, не замечают опасности.

Ниже нормы-20\%) вдумчивость, осторожность, стремление предугадывать возможные последствия своих поступков, которые иногда приводят к пассивности, страхам, к чувству досады и зависти.

В целом результаты исследования однозначно характеризуют всех опрошенных как лиц, сочетающих в себе ярко выраженные типы виктимности. Таким образом, проведенное исследование подтверждает приведенные выше мнения исследователей о взаимной обусловленности в личности преступниц как виктимных признаков, так и признаков посягателей [9].

В корыстных преступлениях, совершаемых женщинами, такая связь практически не наблюдается. Для преступлений корыстной направленности, совершаемых женщинами, характерны ситуации, где основными подтипами виктимности являются лица, сами имеющие корыстные побуждения (например, это характерно для мошенничества, когда объектами посягательства нередко становятся люди, стремящиеся к материальной выгоде) [10]. Но также жертвами подобных преступлений могут быть как излишне доверчивые люди, либо доверчивые в силу возраста (например, дети), а также люди, подверженные суггестии (психологическому воздействию (например, жертвы различных гадалок, так называемого «цыганского гипноза» и т.п.). Также жертвами часто выступают беспечные и неосторожные личности, для которых характерны как самонадеянность, так и отсутствие критического осмысления ситуации или ее последствий.

\section{Conclusion}

Следует отметить, что в умышленных групповых преступлениях женщины часто используются именно с целью создать у жертвы ощущение безопасности, чтобы усыпить бдительность. Это также является и фактором, обусловливающим распространенность некоторых видов женской преступности (краж, мошенничества, незаконного оборота наркотиков, терроризма).

Знание всех этих особенностей является не только криминологически значимым, но и важным для разработки виктимологической профилактики женской преступности. Виктимологическая профилактика женской преступности актуальна, поскольку особенностью насильственной женской преступности является то, что жертвами являются, как правило, лица из ближайшего окружения женщины, члены ее семьи, дети.

Как отмечает Д.В. Синьков [6, с. 32-36] система общесоциальных мер виктимологической профилактики преступного поведения женщин должна включать в себя мероприятия, направленные на устранение гендерных стереотипов в обществе, которые зачастую служат, с одной стороны, источником психической напряженности, эмоциональной возбудимости женщин, а с другой - более предубежденного (пристрастного) отношения к женщинам со стороны мужчин. Прежде всего, речь идет о таких мерах, как укрепление института семьи, поддержка материнства, непринятие и искоренение различных проявлений дискриминации по половому признаку, принятие региональных программ, направленных на преодоление опасной тенденции феминизации бедности и безработицы.

В свете данного аспекта предупреждения женской преступности следует осуществлять мероприятия, направленные на выявление и постановку на учет неблагополучных семей, в которых женщины ведут асоциальный образ жизни. К этому следует добавить, что объектом виктимологической профилактики должны быть и сами женщины. 


\begin{tabular}{l|lr|ll|ll} 
& ISRA (India) & $=\mathbf{1 . 3 4 4}$ & SIS (USA) & $=\mathbf{0 . 9 1 2}$ & ICV (Poland) & $=\mathbf{6 . 6 3 0}$ \\
Impact Factor: & ISI (Dubai, UAE) $=\mathbf{0 . 8 2 9}$ & PUHL (Russia) $=\mathbf{0 . 2 0 7}$ & PIF (India) & $=\mathbf{1 . 9 4 0}$ \\
& GIF (Australia) & $\mathbf{0 . 5 6 4}$ & ESJI (KZ) & $=\mathbf{4 . 1 0 2}$ & IBI (India) & $\mathbf{= 4 . 2 6 0}$ \\
& JIF & $\mathbf{1 . 5 0 0}$ & SJIF (Morocco) $=\mathbf{2 . 0 3 1}$ & & \\
\hline
\end{tabular}

\section{References:}

1. Repeckaya A.L. (1992) Vinovnoe povedenie poterpevshego i problema principa spravedlivosti v ugolovnoj politike. Diss. kand. yurid. nauk. - Irkutsk, 1992. - p. 27.

2. Malkina-Pyh I.G. (2006) Psihologiya povedeniya zhertvy.M.: Izd-vo EHksmo, 2006.. - p. 406.

3. Hatkova F.H. (2004) Viktimologicheskie aspekty zhenskoj prestupnosti. Diss. kand. yurid. nauk. - Rostov, 2004. - p. 94.

4. Miheev R.M. (1974) Lichnost' i povedenie poterpevshego.//Poterpevshij ot prestupleniya. Vladivostok, 1974. - p. 73.

5. Tishchenko M.D. (1999) Kompleksnyj kriminologicheskij analiz prestuplenij, sovershennyh na pochve narkomanii, i problemy ih preduprezhdeniya. Avtoref. dis. kand. yurid. nauk. - Rostov-na-Donu, 1999. - p. 22.

6. Sin'kov D.V. (2009) Nekotorye problemy viktimologicheskoj profilaktiki zhenskoj prestupnosti / D.V. Sin'kov // Rossijskij sledovatel'. - 2009. - № 3. - p. 32-36.
7. Lokteva O.V. (2009) Psihologicheskaya priroda viktimnogo povedeniya. Viktimologiya i ee kategorii v otechestvennoj i zarubezhnoj nauke. Ponyatie zhertvy prestupleniya. Cvetovaya simvolika i psihodiagnostika. EHmpiricheskoe issledovanie cvetovogo profilya lic i viktimnogo povedeniya. - Minsk, 2009.

8. Odincova M.A. (2013) Psihologicheskaya bezopasnost' lichnosti. Praktikum. Uchebnoe posobie dlya studentov. Moskva, MGPPU, 2013.

9. Bartasyuk A.A., Kontanistov I.V. (2013) Osnovnye napravleniya preduprezhdeniya zhenskoj prestupnosti: aktual'nye problemy i perspektivy razvitiya. EHlektronnoe nauchnoe izdanie «Uchenye zametki TOGU» 2013, Tom 4, № 4, p. 539 - 547.

10. Kutina V.P. (2006) Nasil'stvennaya zhenskaya prestupnost' i ee preduprezhdenie: dissertaciya ... kandidata yuridicheskih nauk: 12.00.08 Sankt-Peterburg, 2006. 